\section{(6) OPEN ACCESS}

\title{
Ethics of fertility preservation for prepubertal children: should clinicians offer procedures where efficacy is largely unproven?
}

\author{
Rosalind J McDougall, ${ }^{1,2}$ Lynn Gillam, ${ }^{1,2}$ Clare Delany, ${ }^{2,3}$ Yasmin Jayasinghe ${ }^{4,5}$
}

\begin{abstract}
${ }^{1}$ Melbourne School of Population and Global Health, University of Melbourne, Melbourne, Victoria, Australia ${ }^{2}$ Children's Bioethics Centre, Royal Children's Hospital, Melbourne, Victoria, Australia ${ }^{3}$ Department of Medical Education, University of Melbourne, Melbourne, Victoria, Australia

${ }^{4}$ Paediatric and Adolescent Gynaecology, Royal Children's Hospital, Melbourne, Victoria, Australia

${ }^{5}$ Department of Obstetrics and Gynaecology, Royal Women's Hospital, University of Melbourne, Melbourne, Victoria, Australia
\end{abstract}

\section{Correspondence to}

Dr Rosalind J McDougall, Centre for Health Equity, Melbourne School of Population and Global Health, University of Melbourne 3010, Victoria, Australia; rmcdo@unimelb.edu.au

Received 3 November 2016 Revised 24 April 2017 Accepted 11 July 2017 Published Online First 30 October 2017

\section{(1) crossank $^{2}$}

To cite: McDougall RJ Gillam L, Delany C, et al. J Med Ethics 2018;44:27-31.

\section{ABSTRACT}

Young children with cancer are treated with interventions that can have a high risk of compromising their reproductive potential. 'Fertility preservation' for children who have not yet reached puberty involves surgically removing and cryopreserving reproductive tissue prior to treatment in the expectation that strategies for the use of this tissue will be developed in the future. Fertility preservation for prepubertal children is ethically complex because the techniques largely lack proven efficacy for this age group. There is professional difference of opinion about whether it is ethical to offer such 'experimental' procedures. The question addressed in this paper is: when, if ever, is it ethically justifiable to offer fertility preservation surgery to prepubertal children? We present the ethical concerns about prepubertal fertility preservation, drawing both on existing literature and our experience discussing this issue with clinicians in clinical ethics case consultations. We argue that offering the procedure is ethically justifiable in certain circumstances. For many children, the balance of benefits and burdens is such that the procedure is ethically permissible but not ethically required; when the procedure is medically safe, it is the parents' decision to make, with appropriate information and guidance from the treating clinicians. We suggest that clinical ethics support processes are necessary to assist clinicians to engage with the ethical complexity of prepubertal fertility preservation and describe the framework that has been integrated into the pathway of care for patients and families attending the Royal Children's Hospital in Melbourne, Australia.

\section{INTRODUCTION}

Cancer treatment can significantly affect fertility, including for paediatric patients. There has been a marked increase in survival for paediatric patients with cancer, with rates now over $80 \% .{ }^{1}$ Consideration of future quality of life, including fertility, has thus become an important element of treatment for children with cancer. ${ }^{2}$ While many philosophers have questioned the preference for genetic parenthood specifically (eg, $\operatorname{ref}^{3}$ ) having children who share their genes remains an important goal for many cancer survivors. ${ }^{45}$

The magnitude of the effect of treatment on fertility depends on the specific treatment, and individual risk is variable. In girls, after childhood cancer treatment, the overall risk of infertility is $16 \% .^{6}$ In boys, treatment can deplete sperm, as well as stem cells that would usually maintain sperm production in postpubertal life, reducing the number subsequently able to have children. ${ }^{7} \mathrm{~A}$ range of technologies aimed at preserving fertility are in development, originally offered for adult patients. The challenge in prepubertal patients is that there are no mature ova or sperm cells in the gonadal tissue.

There are interventions aimed at fertility preservation that can be offered to patients of various ages: adults, adolescents and young children who have not yet reached puberty (see table 1 ). Some options have proven efficacy, while others are still considered 'experimental'. Management is individualised according to age and clinical circumstances. There is no consensus around clinical best practice for prepubertal fertility preservation, with many guidelines suggesting it should be governed under a research protocol. ${ }^{5}$

In adults and adolescents, some of these fertility preservation strategies (collection of mature sperm and oocytes) are well established with many live births reported. In contrast, the main strategy for prepubertal children currently lacks proven efficacy for this age group. This option involves surgically removing and freezing ovarian or testicular tissue in the expectation that techniques for the use of this tissue will be developed in the future. ${ }^{8}$ Cryopreservation of ovarian tissue is a more long-standing technique than cryopreservation of testicular tissue. There have been over 60 live births worldwide using ovarian tissue collected in adulthood or late adolescence, ${ }^{9}$ one live birth using tissue from a girl who was pubertal but premenarchal at the time of collection ${ }^{10}$ and news reports of one live birth using ovarian tissue that was harvested prepubertally. ${ }^{11}$ It is estimated that live births from testicular tissue may be decades away. ${ }^{12}$

The very limited evidence for efficacy for tissue collected prepubertally raises an important ethical question: when, if ever, is it ethically justifiable to offer fertility preservation surgery for a prepubertal child? In this paper, we explore the ethical considerations involved in attempting fertility preservation for patients of this age group. We outline a range of burdens and benefits and suggest that these need to be considered on a case-by-case basis for individual children. We argue that, for many children, the balance of benefits and burdens is such that the procedure is ethically permissible but not ethically required. ${ }^{13}$ Where the procedure is determined by the clinicians to have low medical and surgical risk, it then becomes the parents' decision to make with appropriate support. We describe the clinical ethics 


\begin{tabular}{|c|c|c|}
\hline & Prepubertal (ie, children) & Pubertal/postpubertal (ie, adolescents and adults) \\
\hline Males & Freezing testicular tissue & $\begin{array}{l}\text { Freezing ejaculated sperm proven efficacy } \\
\text { Freezing surgically extracted sperm proven efficacy } \\
\text { Freezing testicular tissue }\end{array}$ \\
\hline Females & $\begin{array}{l}\text { Freezing ovarian tissue } \\
\text { Surgery to move ovaries outside the field of } \\
\text { radiation }\end{array}$ & $\begin{array}{l}\text { Freezing ova proven efficacy } \\
\text { Freezing ovarian tissue proven efficacy } \\
\text { Surgery to move ovaries outside the field of radiation } \\
\text { Hormone injections to switch off ovaries during treatment }\end{array}$ \\
\hline
\end{tabular}

Embryo cryopreservation and receiving donated gametes are other options that may be discussed.

process that has been implemented to achieve this case-by-case analysis for patients and families attending the Royal Children's Hospital in Melbourne, Australia.

\section{WHAT IS THE PROCESS AND EVIDENCE FOR ATTEMPTING FERTILITY PRESERVATION PREPUBERTALLY?}

Attempting to preserve fertility in a prepubertal child requires a number of steps. First, the tissue must be safely harvested from the child's ovary or testis. For girls, this may involve the removal of a whole ovary. For boys, only a piece of testicular tissue needs to be removed. The surgery to retrieve the tissue involves small but real risks, including bleeding, infection, scarring, damage to surrounding structures and the risks associated with the general anaesthetic. This latter risk can be minimised if the surgery can be done at the same time as the child is having a general anaesthetic for another element of his or her treatment, ${ }^{14}$ although this is not possible for all patients. With appropriate clinical selection of patients, the chance of a major complication is usually very low.

This tissue then needs to be frozen and stored by an appropriate facility (such as an In Vitro Fertilisation clinic) until the child is an adult. If he or she wants to become a genetic parent, the next step is for the tissue to be grafted back into the body. The tissue then needs to function to produce gametes. (Research is being done to mature the ovarian tissue in vitro, and produce gametes without reimplantation into the patient's body; this would be useful for cancers like leukaemia where the reproductive tissue could have malignant contamination, such that reintroduction of the tissue would reintroduce the malignancy into the patient's body.) ${ }^{1516}$ The final steps would be for the gametes to be fertilised either naturally or via IVF, producing a pregnancy, which is then carried to term, resulting in a live birth.

For both males and females, the retrieval procedure has been found to be safe. ${ }^{17}{ }^{18}$ For females, there is some evidence that ovarian tissue can be collected from a prepubertal girl, frozen, then be reimplanted and begin functioning. The level of function is enough to induce puberty and menstruation. ${ }^{19}$ There has been one reported case of a live birth. ${ }^{11}$ For prepubertal boys, fewer steps in the process have been demonstrated; however, success is considered possible within the lifetime of a boy who might have tissue collected today. ${ }^{12}$

\section{EXISTING ETHICAL GUIDANCE FOR CLINICIANS}

The guidance offered by professional bodies to clinicians about fertility preservation for prepubertal patients is varied and vague. The relevant peak international bodies recommend discussion of the impact of gonadotoxic therapy on fertility with all patientsincluding paediatric patients and their families-prior to treatment. ${ }^{5021}$ Discussion of cancer treatment's impact on fertility is required as part of standard of care, but the guidelines are less clear in relation to discussing possible fertility preservation procedures where these lack proven efficacy. Generally, American guidelines recommend that procedures that do not have established efficacy, such as ovarian tissue cryopreservation in girls or testicular tissue cryopreservation in boys, only be offered under ethically approved research protocols. ${ }^{52}$ UK guidelines have recently recommended that a lower age limit not be used for cryopreservation for cancer patients $^{21}$; however, the options recommended do not include procedures that could be undertaken on prepubertal patients.

Professional guidelines are therefore far from definitive in relation to the ethics of offering prepubertal fertility preservation. They do not address the fundamental ethical question facing clinicians: under what circumstances would it be ethically appropriate to offer fertility preservation for a prepubertal patient? Rather, their statements tend to be too vague to guide individual clinicians and centres and/or to focus on the need for research ethics oversight of these procedures.

As such, it is not surprising that there is significant variation between clinicians and centres in relation to whether and how fertility discussions are approached with different types of paediatric patients with cancer, including prepubertal patients. ${ }^{22}$ There is a lack of definitive data about current practice, but anecdotally few Australian hospitals offer fertility preservation procedures to prepubertal females and only one to prepubertal males. Global numbers are similarly unclear but look to be small; a recent international survey indicates 26 hospitals offering ovarian tissue cryopreservation to girls aged $0-11$ years and 16 hospitals offering testicular tissue cryopreservation to boys aged $0-11$ years. $^{23}$ The 'Edinburgh criteria' developed by Wallace and colleagues constitute one published approach to offering ovarian tissue cryopreservation, including to prepubertal patients. ${ }^{24}$ This set of criteria exclude patients who have had previous gonadotoxic therapy. They also require that the patient is at high $(>50 \%)$ risk of infertility from her treatment. The substantial variation in practice internationally and within institutions reflects, in part, the ethical uncertainty about the status of prepubertal fertility preservation procedures.

\section{ETHICAL CONCERNS IN PRACTICE}

Our clinical ethics service was recently approached by clinicians for ethics support around the issue of surgery aimed at fertility preservation for prepubertal children. Coming from the perspective of evidence-based medicine, clinicians were concerned about offering a procedure that lacked proven efficacy. Was it burdening the child without justification? However, there were also worries about failing to offer a potentially beneficial procedure: attempting fertility preservation is low risk for many children, is an area of rapidly progressing research and relates to becoming a genetic parent, which is important to many cancer survivors. $^{45}$ 
A process of routine referral for clinical ethics case consultation was instituted. Each time fertility preservation was being considered for a prepubertal patient, the case was referred for a clinical ethics discussion. The clinical ethics case consultation process at our hospital uses a multidisciplinary collaborative model that has been described in detail elsewhere. ${ }^{25}$ In a series of clinical ethics case consultations, the burdens and benefits associated with attempting fertility preservation for specific prepubertal children were explored with the treating clinicians. The following discussion draws on our experience of providing these clinical ethics case consultations.

\section{Burdens and risks}

Many of the risks that were raised reflected concerns in the small existing literature on the ethics of paediatric fertility preservation. Quinn and colleagues, drawing on Dudzinski's work on adolescent cancer patients, usefully summarise the key ethical concerns about prepubertal fertility preservation that have been raised in the existing literature:

ensuring that delaying medical treatment for OTC [ovarian tissue cryopreservation] will not result in physical harm to the patient; establishing whether transplantation may result in reseeding of the original disease...; assessing whether oocytes are damaged resulting in miscarriage or developmental delays; issues of informed assent; and establishing protocols for the gametes in the event the patient dies... Additionally, OTC remains controversial as it is unknown whether this will place pressure on Daisy [the two year old patient in the case being analysed] to become a biological parent. ${ }^{26}$ (p. 42; see also ref 16)

A further ethical concern expressed in existing literature is that offering fertility preservation may create false hope, either about the patient's chances of survival or about the likelihood of pregnancy in adulthood. ${ }^{27}$ Undergoing any type of fertility preservation procedure is, of course, no guarantee that the patient will later be able to have a genetically related child. This concern around false hope is particularly acute in relation to prepubertal patients, where the likelihood of pregnancy in adulthood is currently remote and dependent on future studies. Concern has also been expressed about the potential health effects for children conceived using this tissue. ${ }^{28}$ One case of fetal malformation (specifically arthrogryposis-limited motion in the joints) has been described. ${ }^{29}$

Further ethical concerns have been raised in our clinical ethics case consultations. Concerns relating to the risk-benefit ratio of the procedure for that specific child were common. Some were situations where the chance of achieving the desired outcome of fertility was even more remote than the standard case, for example, when the child had already had gonadotoxic therapy. (Gonadotoxic therapy refers to any chemotherapy or radiation treatment which impairs gonadal function. The risk is not absolute and is determined by the agent itself, dose and the age of the patient.) Other concerns involved factors that increased the risks or burdens to the child of the fertility preservation procedure, such as comorbidities that increased surgical risks or a psychosocial situation that increased the distress of undergoing the procedure for the child. The potential ethical concerns are summarised in table 2.

\section{Benefits}

The benefits associated with the procedure were also considered. One benefit is that the procedure at least provides a possible pathway to becoming a genetic parent in the future. The chance may be remote but is likely greater than if the
Table 2 Potential ethical concerns about attempting fertility preservation surgery in prepubertal children

\begin{tabular}{ll}
\hline Before/at time of surgery & In future \\
\hline Delay to cancer treatment & $\begin{array}{l}\text { Impact of surgery on future gonadal } \\
\text { function }\end{array}$ \\
\hline $\begin{array}{l}\text { Family's comprehension that process is } \\
\text { largely unproven for prepubertal tissue }\end{array}$ & $\begin{array}{l}\text { Ongoing cost to family of tissue } \\
\text { storage }\end{array}$ \\
\hline $\begin{array}{l}\text { Decreased quality of tissue due to previous } \\
\text { gonadotoxic therapy }\end{array}$ & $\begin{array}{l}\text { Reseeding the original disease } \\
\text { when tissue reimplanted }\end{array}$ \\
\hline False hope about child's chances of survival & Fate of tissue if child dies \\
\hline $\begin{array}{l}\text { Surgical and anaesthetic risks, sometimes } \\
\text { increased by comorbidities }\end{array}$ & Pressure on patient to use tissue \\
\hline Child's discomfort/distress & $\begin{array}{l}\text { False hope about likelihood of } \\
\text { pregnancy }\end{array}$ \\
\hline Degree of risk to fertility from treatment & Health of offspring conceived \\
\hline
\end{tabular}

fertility preservation procedure was not undertaken. If no tissue is retrieved and reproductive function is lost by childbearing age, there is no chance of using any of the techniques that can be envisaged now and might become reliably effective in the future. Having a genetically related child is important to many people and infertility is often highly distressing. There is substantial empirical evidence that discussions about fertility and fertility preservation are highly valued by patients with cancer. ${ }^{5}$ Survivors who experience infertility report significantly more negative impacts on well-being, relationships and life decisions. ${ }^{4}$ So one key benefit of fertility preservation surgery is that it increases the child's chance of having a genetically related child in the future, which is an important aspect of well-being for many people.

A second important benefit is that fertility preservation demonstrates concern for the child's future fertility. ${ }^{30}$ Even if the procedure is not successful or the tissue is not used by the child in adulthood, attempting fertility preservation demonstrates concern for the child's future fertility, which can be seen as a benefit in itself to the child. He or she may be comforted in adulthood to know that his or her caregivers considered this aspect of well-being and likely future wishes, and tried to keep open the option of genetic children, ${ }^{31}$ even though it was not successful or the patient ultimately chose not to use the tissue. From this perspective, attempting fertility preservation respects the child as a future adult.

\section{THE NEED FOR AN INDIVIDUAL RISK-BENEFIT ASSESSMENT}

In our view, these benefits justify offering the procedure in cases where the surgery is low risk, and the potential benefits are not further reduced by some additional feature of the child's situation. The potential benefits of the procedure are sufficient that children should not be excluded from accessing fertility preservation surgery in situations where the potential burdens are absent or mitigated. Some of the potential burdens (such as delay to treatment or creating false hope) can be addressed with appropriate organisational systems and support for clinicians to ensure good parental understanding of the procedure. Some of the burdens will not apply to specific children (such as increased risks of surgery because of comorbidities or lesser benefit because of previous gonadotoxic therapy). Thus, we suggest that it is sometimes ethically justifiable for doctors to offer fertility preservation for prepubertal patients. Although the degree of benefit is low, so too is the degree of burden in many cases. When the medical team 
Box 1 Example cases of prepubertal fertility preservation.

(These cases are representative amalgams and do not describe particular patients.)

\section{Ethically permissible}

Kate is a 5-year-old girl diagnosed with brain cancer. She is about to start treatment that gives her a $70 \%$ chance of survival but carries a high risk of significantly compromising her future fertility. Her parents are keen to pursue surgery aimed at fertility preservation for Kate, as long as there is no delay to Kate's cancer treatment. The fertility preservation procedure could be done at the same time as a procedure needed for Kate's cancer treatment, so no additional general anaesthetic would be necessary. Kate has not had any previous gonadotoxic treatment. The gynaecologist explains that there has only been one live birth worldwide, so fertility preservation is largely unproven for children of this age. She also explains that the surgery involves small but real risks. The parents clearly understand the risks and the lack of proven efficacy, but still want to proceed. They accept that, if Kate dies, the tissue will be destroyed as is required by law in their state. Kate's doctors and her parents explain the procedure to Kate in an age-appropriate way, and she is willing to go ahead.

\section{Ethically problematic}

Lizzie is a 5-year-old girl diagnosed with brain cancer. Like Kate, she is about to start treatment that gives her a $70 \%$ chance of survival but carries a high risk of significantly compromising her future fertility, and her parents are keen to pursue surgery aimed at fertility preservation as long as there is no delay to cancer treatment. Her situation is similar to Kate's in terms of the comprehensive information given, the parents' understanding and the lack of previous gonadotoxic treatment. However, for Lizzie, the fertility preservation surgery would need to be done as a stand-alone procedure. Furthermore, Lizzie is sometimes very anxious in hospital, particularly about surgical procedures. In Lizzie's case, the situation is more ethically complex and offering the procedure may not be ethically justified.

judges that this low-benefit/low-burden situation applies, the procedure is ethically permissible but not ethically required; it is the parents' decision to make.

This is not to suggest that parents ought to be abandoned to solo decision making in this area, without information, guidance and recommendations from the child's healthcare team. Of course, the decision making process around fertility preservation in prepubertal children will include the clinicians and the parents (and the child, in a developmentally appropriate way). Parents generally want to share decision making with clinicians, although role preferences are individual and situation specific. The key point is that when attempting fertility preservation is low benefit/low burden, parents may justifiably choose either to pursue or to decline the procedure.

\section{A CLINICAL ETHICS PROCESS TO SUPPORT CLINICIANS NAVIGATING THE ETHICAL COMPLEXITY OF PREPUBERTAL FERTILITY PRESERVATION}

Given that the procedure will be ethically justifiable in some cases and not others, the key challenge for clinicians lies in assessing whether each specific case is one in which offering fertility preservation is ethically justifiable. We suggest that there is an important role here for clinical ethics support. Clinical ethics review is best suited to the individualised case assessment that is necessary in this area. Research ethics processes are necessary too but these focus on the research protocol at a much more general level. Exclusive reliance on research ethics processes does not allow the individualised ethical assessment that is necessary in relation to prepubertal fertility preservation procedures. (A very important feature of the research ethics protocol is collection of outcome data, but this can also be achieved by participation in a clinical registry.) Clinical ethics review enables consideration and promotion of each individual child's interests, rather than relying on an overall ethical assessment of a scientific protocol.

We have developed a process of clinical ethics oversight for prepubertal fertility preservation surgical procedures at the Royal Children's Hospital, Melbourne (as one part of a comprehensive approach to governance of paediatric fertility preservation at this hospital). The aim is to ensure that ethical reflection is built into the care pathway for each individual child in this situation. Rather than requiring that patients access the procedure only as part of a research protocol, we have developed a clinical ethics process that focuses on assessing potential burdens and benefits associated with the procedure for each individual patient.

The process began with routine referral to clinical ethics for prepubertal patients for whom fertility preservation was being considered and has since evolved into a clinician-led process using a checklist of questions (box 2). This framework aims to distinguish cases that are ethically straightforward from those that are more ethically complicated. After a series of clinical ethics case consultations, we noticed that the same potential concerns were being explored in each discussion. We captured these into a list that we began to use in our case discussions of individual children in order to ensure that the discussions were comprehensive. We also continued to create space for any other concerns to be discussed, beyond those included on the list. Clinicians now use the framework of questions themselves in a written format to work through the potential ethical issues for a specific child. This continues to be supported by the clinical ethics team; an ethicist reviews the written responses. The option remains for a full clinical ethics case discussion if the ethicist, clinician or family remains uncertain about the case.

This list of questions is an example of an inductively derived checklist that highlights ethically relevant considerations. The checklist does the work of stimulating and capturing ethical deliberation but without reducing the ethical concerns to a 'tickbox' or procedural checklist. In this way, it represents a tool for promoting ethical literacy for clinicians involved in this area of work.

\section{CONCLUSION}

We have argued that it is sometimes ethically justifiable for doctors to offer fertility preservation surgery for prepubertal patients and that a case-by-case ethical analysis is necessary. Although the degree of benefit offered by the procedure is currently low, so too is the degree of burden in many cases. When this low-benefit/low-burden situation applies, offering the procedure is ethically justified.

Our view is that relying exclusively on the research ethics process to govern fertility preservation does not best protect children from the risk of harm associated with the procedure nor does it best enable access to this potentially beneficial procedure. Alongside research ethics review of relevant study protocols, the 
Box 2 Royal Children's Hospital, Melbourne ethics framework for prepubertal fertility preservation

The series of questions explicitly prompt reflection on the ethical concerns associated with the procedure. The clinician is asked:

- About the child's condition, proposed treatment and expected outcome

- To specify the level of risk to fertility posed by the treatment; and then

1. Is there reduced potential for retrieving viable tissue from this child? (eg, damage to gonadal tissue by previous treatment or the underlying condition)

2. Will the fertility preservation procedure take place at the same time as a treatment procedure?

3. Will fertility preservation delay the start of treatment?

4. What risks or possible complications are associated with the fertility preservation procedure for this child?

5. Do the parents have a good understanding (A) that the procedure will not guarantee fertility in the future but simply offers a possibility, dependent on future technology and (B) that it has some degree of risk?

6. If the child is old enough to understand the procedure, even in basic terms, $(A)$ has the procedure been explained to the child and (B) does the child have any objections or worries?

7. Are there any other relevant matters or concerns?

If the answers indicate any ethical concerns (eg. yes to 1,3 or $6 \mathrm{~B}$, or no to 2,5 or $6 \mathrm{~A})$, this triggers further formal clinical ethics consultation.

hospital's clinical ethics service can be used as a resource for providing timely ethical review that is responsive to individual patient circumstances.

In this paper, we have focused on the ethical issues at a clinical level, looking at the fundamental question of 'when, if ever, is it ethically justifiable for a doctor to offer fertility preservation surgery for a prepubertal child?' However, beyond this doctorpatient level, there are also significant ethical issues at a broader social and structural level. These ethical questions relate particularly to costs (of the initial procedure, tissue storage and subsequent fertility-related treatment in adulthood) and, relatedly, to equity of access. There remains an urgent need for substantial and detailed ethical analysis of these broader questions.

Contributors All authors conceptualised the paper's argument, drawing on their experience in clinical ethics case consultations together. RJM wrote the first draft, which was then substantially edited by LG, CMD and YJ.

\section{Competing interests None declared.}

Provenance and peer review Not commissioned; externally peer reviewed.

Open Access This is an Open Access article distributed in accordance with the Creative Commons Attribution Non Commercial (CC BY-NC 4.0) license, which permits others to distribute, remix, adapt, build upon this work non-commercially, and license their derivative works on different terms, provided the original work is properly cited and the use is non-commercial. See: http://creativecommons.org/ licenses/by-nc/4.0/

(c) Article author(s) (or their employer(s) unless otherwise stated in the text of the article) 2018. All rights reserved. No commercial use is permitted unless otherwise expressly granted.

\section{REFERENCES}

1 Australian Institute of Health and Welfare. Cancer in adolescents and young adults in Australia, 2011. http://www.aihw.gov.au/WorkArea/DownloadAsset.aspx?id= 10737420600 (accessed 20 Sep 2016).
2 Nathan PC, Greenberg ML, Ness KK, et al. Medical care in long-term survivors of childhood cancer: a report from the childhood cancer survival study. J Clin Oncol 2008;26:4401-9.

3 Baylis F, McLeod C, eds. Family making: contemporary ethical challenges. New York: Oxford University Press, 2014.

4 Canada AL, Schover LR. The psychosocial impact of interrupted childbearing in long term female cancer survivors. Psychooncology 2012;21:134-43.

5 Loren AW, Mangu PB, Beck LN, et al. Fertility preservation for patients with cancer: American Society of Clinical Oncology clinical practice guideline update. J Clin Oncol 2013;31:2500-10.

6 Barton SE, Najita JS, Ginsburg ES, et al. Infertility, infertility treatment, and achievement of pregnancy in female survivors of childhood cancer: a report from the Childhood Cancer Survivor Study cohort. Lancet Oncol 2013;14:873-81.

7 Green DM, Kawashima T, Stovall M, et al. Fertility of male survivors of childhood cancer: a report from the Childhood Cancer Survivor Study. J Clin Oncol 2010;28:332-9.

8 Anderson RA, Mitchell RT, Kelsey TW, et al. Cancer treatment and gonadal function: experimental and established strategies for fertility preservation in children and young adults. Lancet Diabetes Endocrinol 2015;3:556-67.

9 Donnez J, Dolmans MM. Ovarian cortex transplantation: 60 reported live births brings the success and worldwide expansion of the technique towards routine clinical practice. J Assist Reprod Genet 2015;32:1167-70.

10 Demeestere I, Simon P, Dedeken L, et al. Live birth after autograft of ovarian tissue cryopreserved during childhood. Hum Reprod 2015;30:2107-9.

11 Walsh F. Woman has baby using ovary frozen in childhood. BBC News 2016 http:// www.bbc.com/news/health-38312995 (accessed 27 Mar 2017).

12 Clark AT, Phillips BT, Orwig KE. Male fertility in the test tube. Nat Med 2011:17:1564-5

13 McDougall R, Delany C, Gillam L, eds. When doctors and parents disagree: ethics, paediatrics and the zone of parental discretion. Sydney: Federation Press, 2016.

14 Patrizio P, Butts S, Caplan A. Ovarian tissue preservation and future fertility: emerging technologies and ethical considerations. J Natl Cancer Inst Monogr 2005:34:107-10.

15 Dolmans MM, Luyckx V, Donnez J, et al. Risk of transferring malignant cells with transplanted frozen-thawed ovarian tissue. Fertil Steril 2013:99:1514-22.

16 Zoloth L, Backhus L, Woodruff T. Waiting to be born: the ethical implications of the generation of "NUBorn" and "NUAge" mice from pre-pubertal ovarian tissue. Am J Bioeth 2008:8:21-9.

17 Fabbri R, Vicenti R, Macciocca M, et al. Cryopreservation of ovarian tissue in pediatric patients. Obstet Gynecol Int 2012;2012:1-8 www.ncbi.nlm.nih.gov/pmc/articles/ PMC3306942/

18 Faure A, Bouty A, O'Brien M, et al. Testicular biopsy in prepubertal boys: a worthwhile minor surgical procedure? Nat Rev Urol 2016;13:141-50.

19 Poirot C, Abirached F, Prades M, et al. Induction of puberty by autograft of cryopreserved ovarian tissue. Lancet 2012;379:588.

20 Amato P. Ethics committee of American Society for Reproductive Medicine. Fertility preservation and reproduction in patients facing gonadotoxic therapies: a committee opinion. Fertil Steril 2013;100:1224-31.

21 National Institute for Health and Care Excellence. Clinical guideline - fertility problems: assessment and treatment, 2013. www.nice.org.uk/guidance/cg156 (accessed 7 Jan 2016).

22 McQuillan SK, Malenfant D, Jayasinghe YL, et al. Audit of current fertility preservation strategies used by individual pediatric oncologists throughout Australia and New Zealand. J Pediatr Oncol 2013;1:112-8.

23 Rashedi AS, de Roo SF, Ataman LM, et al. Survey of fertility preservation options available to patients with cancer around the globe. J Glob Oncol:JG0.2016.008144.

24 Wallace WH, Smith AG, Kelsey TW, et al. Fertility preservation for girls and young women with cancer: population-based validation of criteria for ovarian tissue cryopreservation. Lancet Oncol 2014;15:1129-36.

25 McDougall RJ, Notini L. What kinds of cases do paediatricians refer to clinical ethics? Insights from 184 case referrals at an Australian paediatric hospital. J Med Ethics 2016:42:586-91.

26 Quinn GP, Stearsman DK, Campo-Engelstein L, et al. Preserving the right to future children: an ethical case analysis. Am J Bioeth 2012:12:38-43.

27 Grundy R, Larcher V, Gosden RG, et al. Fertility preservation for children treated for cancer (2): ethics of consent for gamete storage and experimentation. Arch Dis Child 2001;84:360-2

28 Cohen CB. Some perils of "waiting to be born": fertility preservation in girls facing certain treatments for cancer. Am J Bioeth 2008:8:30-2.

29 Meirow D, Ra'anani H, Shapira M, et al. Transplantations of frozen-thawed ovarian tissue demonstrate high reproductive performance and the need to revise restrictive criteria. Fertil Steril 2016:106:467-74

30 McDougall $R$. The ethics of fertility preservation for paediatric cancer patients: from offer to rebuttable presumption. Bioethics 2015:29:639-45.

31 Feinberg J. The child's right to an open future. In: Aikin W, LaFollette $\mathrm{H}$, eds. Whose child? Children's rights, parental authority, and state power. Littlefield, Totowa, 1980:124

32 Stern C, Conyers R, Orme L, et al. Reproductive concerns of children and adolescents with cancer: challenges and potential solutions. Clin Oncol Adolesc Young Adults 2013:3:63-78 